\title{
A 70 años de la Constitución de 1949. Su plena vigencia conceptual
}

\author{
Carlos Raimundi ${ }^{1}$ | Universidad Nacional de La Plata
}

Revista Derechos en Acción ISSN 2525-1678/ e-ISSN 2525-1686

Año 4/No 11 Otoño 2019 (21 marzo a 21 junio), 643-649

DOl: https://doi.org/10.24215/25251678e293

\section{Introducción}

El último 9 de marzo se cumplieron 70 años de la promulgación de la Constitución Nacional de 1949. Se trata de una cuestión de absoluta actualidad, por lo vigente de la necesidad de construir un marco institucional de profundo contenido humanista, social, comunitario, que es lo que expresa la doctrina social a la que pertenece esa Constitución. Es un tema cuya importancia no sólo se sostiene sino que crece con el tiempo.

Indudablemente, relanzar la trascendencia de la Constitución de 1949 implica una toma de posición muy intensa en la batalla cultural. Se trata de retomar el sentido de sus grandes contenidos, de sus grandes ejes. Para lo cual hay que enfrentarse con el discurso liberal férreamente inculcado desde la segunda mitad del siglo XIX y sostenido hasta hoy, que es profundamente contradictorio. Porque nos habla de una Constitución que, según ese discurso liberal, había sido sancionada por una tiranía surgida -paradójicamente- de la voluntad mayoritaria del pueblo. Y que es resultado del estricto cumplimiento de todos los requisitos procesales establecidos por la Constitución de 1853. La Constitución de 1949 goza pues, de legitimidad democrática sustantiva porque hubo un fuerte respaldo popular y también legitimidad democrática procedimental.

\footnotetext{
Abogado, profesor de la Facultad de Ciencias Jurídicas y Sociales de la Universidad Nacional de La Plata.
} 
Sin embargo, se la describe como una Constitución tiránica y facciosa. Y, por ese motivo, se la sustituyó entre 1956 y 1957, bajo la excusa de volver a una Constitución "democrática", la de 1853. Pero se lo hace a través de un bando militar, seguido de una elección de constituyentes de la que estuvo ausente por proscripción la fuerza política mayoritaria. Estamos, pues, en una etapa de reconstrucción de legitimidad de la Constitución de 1949.

La ilegítima reforma constitucional de 1957 es una comprobación de la imagen que expresa Álvaro García Linera en cuanto a cómo los procesos populares se desarrollan por "oleadas". Es decir, la marea sube, luego baja, pero siempre algo deja. Así, aquella reforma no tuvo más remedio que resumir los derechos sociales conquistados durante el primer peronismo, en el escueto artículo 14 bis que fue añadido. Es decir, el régimen militar pudo bombardear, fusilar y proscribir, pero no pudo quitar del alma de los trabajadores y trabajadoras argentinas el instituto del aguinaldo y otros derechos sociales. La marea bajó, pero algo dejó...

\section{Presupuestos de legitimidad}

Nuestra concepción sobre el constitucionalismo social en general y sobre la Constitución de 1949 en particular parte de ciertos presupuestos. El primero, es que una Constitución es la enunciación normativa de un modelo político. No existe Constitución que se limite a una arquitectura jurídica en abstracto, apta para ser aplicada indistintamente a cualquier modelo social y político. A un modelo liberal burgués corresponde un tipo de Constitución y a un modelo nacional y popular corresponde otro tipo de Constitución, no hay neutralidad posible. La pretendida equidistancia solicitada por el formalismo republicano liberal se convierte en un silencio pasivo que convalida la correlación de fuerzas del statu quo, y juega siempre a favor del poder dominante. Es como si alguien se vanagloriara, en nombre de la neutralidad, de no intervenir en una pelea callejera de cuatro contra uno. 
El segundo presupuesto es que si consideramos históricamente agotado el modelo de acumulación con centro en el capital financiero globalizado, debemos considerar igualmente agotado el modelo institucional y de representación política que lo sostiene. Resulta contradictorio -como lo certifica la interrupción de los procesos populares latinoamericanos del siglo XXI- consolidar instituciones económicas no neoliberales a partir del modelo de representación política impuesto por el neoliberalismo.

El tercer presupuesto es la necesidad de reapropiarnos de la palabra República, y no entregarla al formalismo demoliberal. Para éste, la República es un sistema de mediaciones que se ha complejizado tanto con la evolución de las fuerzas económicas, que termina tergiversando y subvirtiendo la voluntad popular. Las decisiones políticas, aún aquellas tomadas por gobiernos surgidos del voto, suelen terminar siendo contrarias a la voluntad expresada por el votante. El pueblo vota, pero no decide. Por lo tanto, un concepto más sustancial de República es aquel que se refiere a la preocupación, la administración y el sentido en que se administran los bienes públicos, los bienes universales. El pleno empleo, el desarrollo del mercado interno, las paritarias, las Universidades populares, por poner pocos ejemplos, son instituciones profundamente republicanas.

El cuarto presupuesto es que no hay contradicción entre igualdad y libertad. Cuanto más alto es el nivel de igualdad, hay mayores herramientas para desarrollar la libertad individual. Lo que no existe es una fórmula universal y atemporal para combinar ambos principios, porque cada pueblo lo resuelve de acuerdo con su historia, su cultura, su realidad económico social. Se trata de una construcción histórica y social. Eso sí, cuanto mayores herramientas de igualdad tiene una sociedad, más cohesionada se encontrará y por lo tanto mejor predispuesta a que cada uno de sus integrantes desarrolle su propio plan de vida, es decir, haga ejercicio respetuoso, humanista y solidario de su libertad individual. 


\section{La Constitución liberal de 1853}

¿En qué consiste la orientación liberal de la Constitución de 1853? En que responde a un modelo de época, signado por el liberalismo como doctrina filosófica y económica y por la burguesía como clase social en ascenso. A diferencia de los Estados Unidos, la Argentina no se constituye a partir de una burguesía productiva sino de una oligarquía terrateniente, que entreteje una alianza de clase con las fuerzas del orden. Y se consolida a través del proceso de modernización de carácter elitista, cuyos mayores ejecutores son Alberdi, Sarmiento, Mitre y Roca, pese a sus disidencias y sus disputas.

En el siglo XIX, la segunda revolución industrial determina una nueva división internacional del trabajo, entre Estados productores de materias primas y Estados que transforman esas materias primas, las comercian con valor agregado por el trabajo incorporado, y se convierten en potencias industriales. El continente americano vivió tres guerras civiles en esta etapa, que determinaron, según cómo se resolvió cada una, su inserción en esa división entre el desarrollo industrial y el subdesarrollo de la primarización. En los Estados Unidos, entre 1861 y 1865 , tuvo lugar la guerra entre los estados del norte industrialista y los estados del sur agropecuario, y se definió en favor de los primeros. Así, aquel país se incorporó a la nueva fase del capitalismo como país industrial, con la ventaja respecto de Europa, que obtenía las materias primas dentro de su propio territorio, prefigurando su condición de liderazgo mundial.

Contemporáneamente con eso, América Latina sufre dos guerras civiles: la guerra contra el Paraguay, entre 1864 y 1870, en la que las tres oligarquías latifundistas del litoral argentino, el sur de Brasil y el Uruguay, derrotan el proyecto industrial encarnado por Gaspar Francia y los gobiernos de Carlos y Francisco Solano López. Y, entre 1879 y 1883, tiene lugar la guerra del Pacífico donde las empresas británicas financian a las tropas chilenas para anexar territorios del Perú, privar de la salida del mar a Bolivia y romper la confederación productiva 
peruano boliviana. Estas dos guerras, a la inversa de lo sucedido en Norteamérica, ubican a nuestra región como productora de materias primas, lo cual con el tiempo irá ensanchando la brecha económica y tecnológica entre naciones industrializadas y subdesarrolladas, y al mismo tiempo reproducirá esa misma brecha a nivel de la desintegración social al interior de nuestros Estados. La brecha entre países ricos y pobres se apoyará en oligarquías internas que irán concentrando cada vez más la riqueza al servicio de los factores de poder externo.

En definitiva, aquellos principios políticos de libertad, igualdad y fraternidad enarbolados por la Revolución Francesa, cedieron ante los principios económicos de "laissez faire, laissez passer" (dejar hacer, dejar pasar), y terminaron por subordinar toda nuestra estructura constitucional al servicio de la propiedad privada de unas pocas familias.

\section{El contexto de la Constitución de 1949}

Así como el siglo XIX corresponde a la burguesía y el liberalismo, la Constitución de 1949 se enmarca en el constitucionalismo social de la primera parte del siglo XX. Junto al proletariado industrial surgieron las primeras organizaciones sindicales, los partidos de raigambre socialista y las sucesivas Constituciones derivadas de esas nuevas ideas. La constitución mexicana sobreviniente a la revolución campesina de 1910 y la constitución socialdemócrata alemana son algunos de sus antecedentes. Pero la Constitución justicialista no traspola linealmente sus postulados, sino que los integra con la noción de Comunidad Organizada develada por Juan Perón en el Congreso de Filosofía de Mendoza y con el concepto de Tercera Posición en el plano geopolítico. El peronismo, como representación política de la clase trabajadora, añade a la estricta lucha de clases sostenida por el marxismo, la idea de la emancipación nacional, habida cuenta del neo-colonialismo que no era una cuestión central en Europa pero que sí afectaba duramente a los estados dependientes latinoamericanos. Una batalla emancipatoria en la 
cual estarán comprometidos no sólo los trabajadores, sino otros sectores de la vida nacional. De todo ese plexo emanan las ideas de la función social de la propiedad, la propiedad pública de los recursos naturales y los sujetos colectivos de derechos como la niñez, la ancianidad y los trabajadores, en coexistencia con los derechos individuales.

\section{Actualización de los principios de 1949}

¿Cómo deberían actualizarse hoy esos principios? La tercera posición probablemente deba hacerlo en términos de erigir a nivel mundial un sujeto profundamente popular, humanista y democrático, frente a la desmesura irracional del capital financiero globalizado que es el sujeto neoliberal y lo que aparece como su contracara, sin serlo verdaderamente, que es el sujeto neofascista.

En el actual contexto regional y mundial, un nuevo modelo económico, social, político y cultural, de carácter nacional, popular, democrático, latinoamericanista y feminista, debe apoyarse en la distribución de la riqueza y la renta monopólica, y la dinamización de los factores productivos del mercado interno y regional.

Propongo, sólo a modo de ejemplo, los siguiente puntos.

La renta de origen agropecuario. El trabajo de los grupos económicos vinculados al agronegocio, ya sea desde la perspectiva de las semillas, los agroquímicos o la cadena exportadora, debe ser remunerado. Pero no debe confundirse ese trabajo realizado con la renta extraordinaria. Porque el trabajo podría ser el mismo en otras regiones del planeta y no obtener la misma renta, debido al rendimiento diferencial entre la fertilidad que distingue a nuestras pampas con la de otras regiones menos productivas. Es decir, la renta extraordinaria de la tierra no depende del trabajo en sí mismo únicamente, sino de las condiciones naturales, recurso que es de propiedad pública y no privada, y mucho menos monopólica. Por lo tanto, los grupos deben ser recompensados por su trabajo, pero es el 
pueblo argentino el beneficiario de esa renta extraordinaria, que proviene de las condiciones naturales de nuestro territorio y le pertenece al Pueblo como sujeto colectivo.

La producción pública de aquellos medicamentos destinados a cubrir las patologías más comunes, debe disminuir sensiblemente el precio de los mismos y favorecer el acceso de vastos sectores del Pueblo.

La renta de los grandes oligopolios que manejan los servicios esenciales como el agua, el gas o la electricidad, debe adecuarse al principio de que se trata de derechos humanos fundamentales y no de bienes de mercado. Por lo tanto, ningún interés privado, por poderoso que sea, puede sobreponerse a una cuestión de orden público de esta jerarquía.

El derecho a la información es público y -de acuerdo con las nuevas tecnologías- se propaga por distintas vías pero siempre a través del espacio público. En consecuencia, si un derecho público se difunde a través de un espacio púbico, su administración debe ser pública. Por lo tanto, los permanentes saltos tecnológicos en esta materia deben volcarse en favor del principio democrático y republicano de la pluralidad de voces, y no ser propiedad privada de un puñado de grupos empresarios.

En definitiva, se trata de una serie de pinceladas históricas y conceptuales que justifican la plena vigencia de las ideas-fuerza que impulsaron la Constitución de 1949. 